\title{
MANAGEMENT, IT SECURITY AND RISK MANAGEMENT ISSUES IN VIET NAM TOURISM INDUSTRY
}

\author{
PHAM MINH DAT ${ }^{1}$, DUONG THI HONG NHUNG ${ }^{2}$, DINH TRAN NGOC HUY ${ }^{3}$, DO THI THU HUYEN \\ \& NGUYEN DUY MAU ${ }^{5}$ \\ ${ }^{1}$ Research Scholar, Thuongmai University, Hanoi Viet Nam ${ }^{*}$ \\ ${ }^{2}$ Research Scholar, Thuongmai University, Hanoi Viet Nam \\ ${ }^{3}$ Research Scholar, Banking University, Ho Chi Minh city Viet Nam MBA, Graduate School of International Management, \\ International \\ University of Japan, Niigata, Japan \\ ${ }^{4}$ Research Scholar, Thuongmai University, Hanoi Viet Nam \\ ${ }^{5}$ Research Scholar, DaLat University, vietnam
}

\begin{abstract}
IT security and IT risk management is becoming vital part in the whole business and risk management system for airlines and tourism industries in recent years, esp. during the digital technology revolution.

Systemic risk, different from non-systematic risk, is the risk affecting (almost) all stocks in the market, so it is also called market risk such as GDP, interest rates, inflation, war ...

The purpose of this paper is to measure and evaluate beta values of tourism and airlines industry, under challenges in the market such as pricing and supporting services, during

post-low (L) inflation period 2015-2017. In fact, after finding results, we realize that beta values are acceptable, i.e lower than 1, in tourism and airlines sector whereas volatility or frisk has declined slightly, shown by equity beta var values.

Finally, this paper provides some ideas that could provide companies and government more evidence in establishing their policies in governance. This is the complex task but the research results shows us warning that the market risk volatility might be higher during the post-low inflation period 2015-2017. And our conclusion part will recommend some policies and plans to deal with it. Finding new potential markets and credit and financing policies are among directions for tourism \& airline companies. Also, it accompanies with IT risk management policies.

JEL classification numbers: G00, G390, C83

KEYWORDS: Risk Management, Asset Beta, Financial Crisis, Tourism \& Airline Industry, Policy
\end{abstract}

Received: Jun 06, 2020; Accepted: Jun 26, 2020; Published: Jun 29, 2020; Paper Id.: IJMPERDJUN2020130

\section{INTRODUCTION}

Vietnam tourism and airlines industries are under challenges and difficulties after Covid 19 impacts. It needs to measure market risk and propose risk management plans as well as better business plans to recover soon. The Ministry of Culture, Sports and Tourism has proposed to provide a financial package for tourism businesses to cancel tours instead of canceling tours. This financial package will support businesses issuing "tour vouchers" with a term of 12 - 18 months with a value equivalent to the tour booked for customers who are unable to make the trip 
due to the epidemic situation or the Other force majeure cases.

Besides, in this digital technology era, the role of Information Technology (IT) and Internet is increasingly important. It will contribute to increase e-commerce solutions for doing business in these above sectors.

\section{Body of Manuscript}

\section{Research Issues}

The main goal of this study is recognizing how much volatility in risk level in tourism\& airline industry, as well as levels of increasing or decreasing of market risk, measured by beta CAPM in these sectors, under hypotheses.

The hypotheses under testing is: whether small or large fluctuation of beta values and comparing beta in 2 periods crisis and post -L inflation time.

Then we continue to recommend some proper policies to recover.

\section{LITERATURE REVIEW}

A model by Fama and French (2004) stated that significant values are value and size, in 3 factor model, so stock return depends on market beta and market cap. Beta.

Then, Tolga et al. (2015) found out in systematic risk estimation, there are measurement errors in periods 19691989.

Also, Hang Bai et al. (2018) mentioned CAPM in a single variable model, has failed to explain the value premium w/o disasters. Then the relation of beta -return "flat", because of error in beta measure. Next, Shetty and Janet (2019) mentioned that minimizing the systematic risk is always difficult than unsystematic risk

Next, a finding by Dimitrov (2006) shows us leverage and stock returns has negative correlation significantly.

Then, Umar (2011) found that the higher the leverage, the better CG structure the firm has (more than 47\%).

Last but not least, Denis et al (2019) stated that leverage impact on correlation between beta and volatility. Result revealed that the bias reduced overall in case stressed financial markets.

Finally, The cost of using capital Ke is calculated according to the following formula:

Rf: Risk free rate

The risk-free rate is the interest rate at which the risk ratio of an asset is close to zero.

Normally, the risk-free rate will be equal to the interest rate of 10-year government bonds.

Beta is a measure of the volatility of a stock compared to the general market.

Risk premium $=\mathrm{Rm}-\mathrm{Rf}$

Risk premium is the bonus when you invest in stocks (high risk), compared to holding other assets (low risk).

Rm: Required market return

\section{Conceptual Theories}

First, financial flexibility and rising capital markets create improved business opportunities for businesses. Organizations 
should change the equity capital structure to change the fixed cost to variable cost structure. Although borrowing will help an organization improve its competitiveness, the company tends to maximize its debt because the vulnerability is not so anxious due to so much debt financing. Leverage will aid in its success and development over the company's lifetime.

\section{METHODOLOGY}

We use quantitative method to make risk assessment from live data on Vietnam stock exchange for listed tourism and airlines industry firms in Vietnam with tax rate $25 \%$ at that time. After calculating and comparing risk indexes such as beta CAPM we propose suitable policies and include risk management plans.

Some proper policies can be recommended after study.

\section{MAIN RESULTS}

\section{General Data Analysis}

We get some analytical results from the research sample with12 listed firms in thetourism \& airline market with the live date from the stock exchange.

\section{Empirical Research Findings and Discussion}

The study review contains twelve (12) listed entities on the tourism and airlines market with live data. Next, we measure these companies ' stock beta valuation and use their capital flexibility to measure their asset beta values. The average asset beta mean is calculated to be $0,092,0,059$, i.e acceptable $(<1)$ with current leverage. We also note that values of asset beta var has reduced i.e smaller than $(<)$ equity beta var.

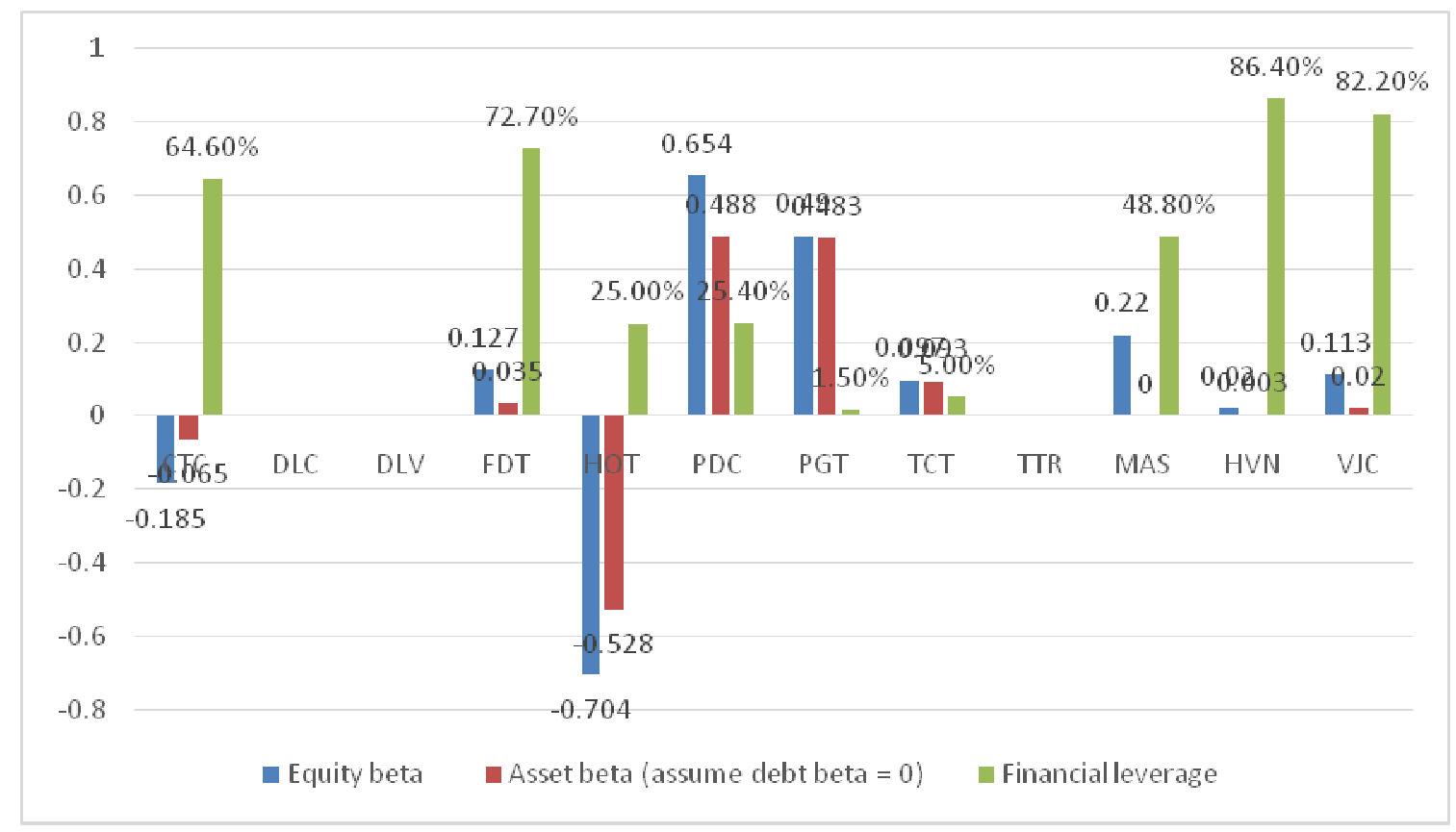

Figure 1: Measuring Market Risk Via Beta CAPM in above Industries 


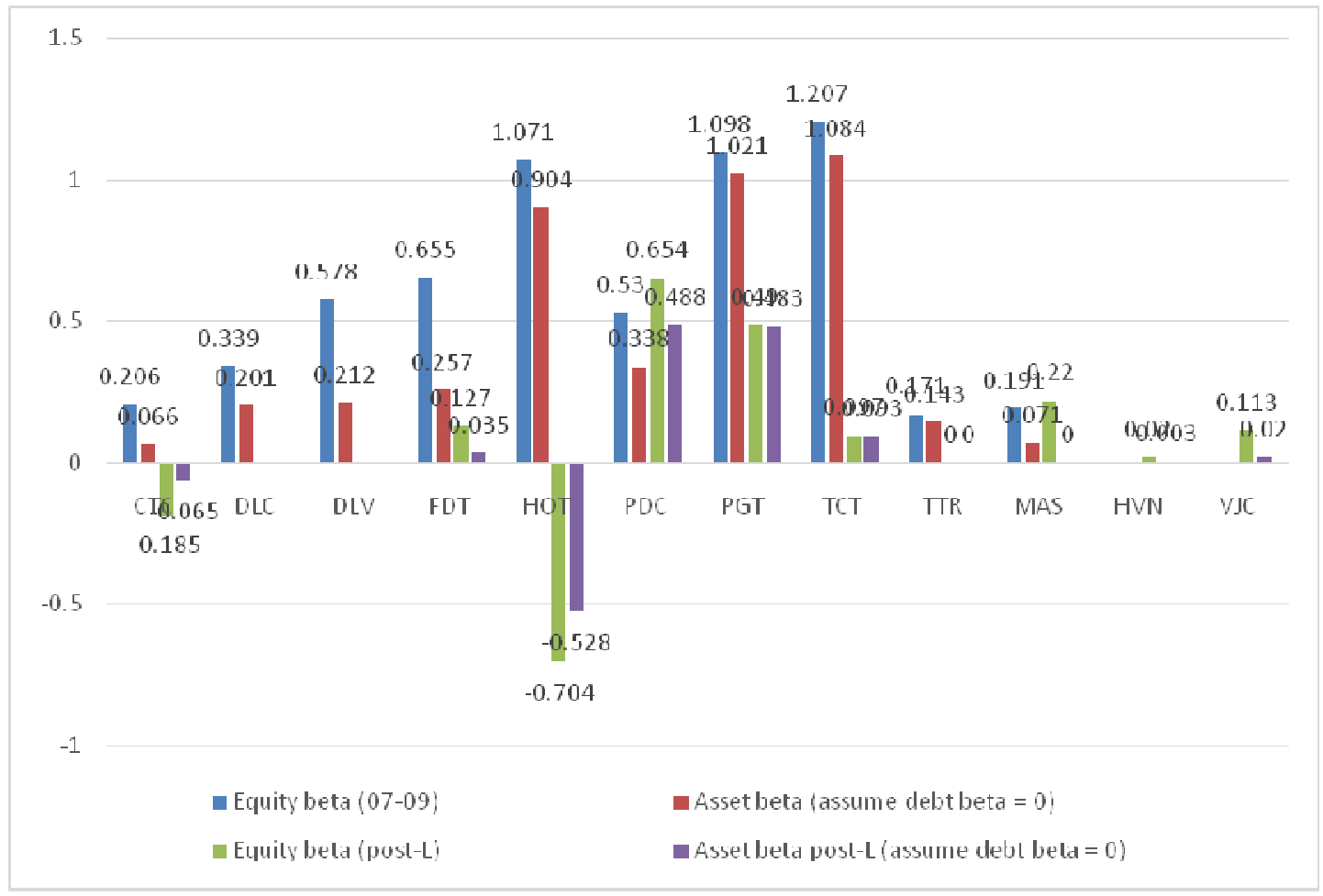

Figure 2: Comparing Beta CAPM in 2 Periods.

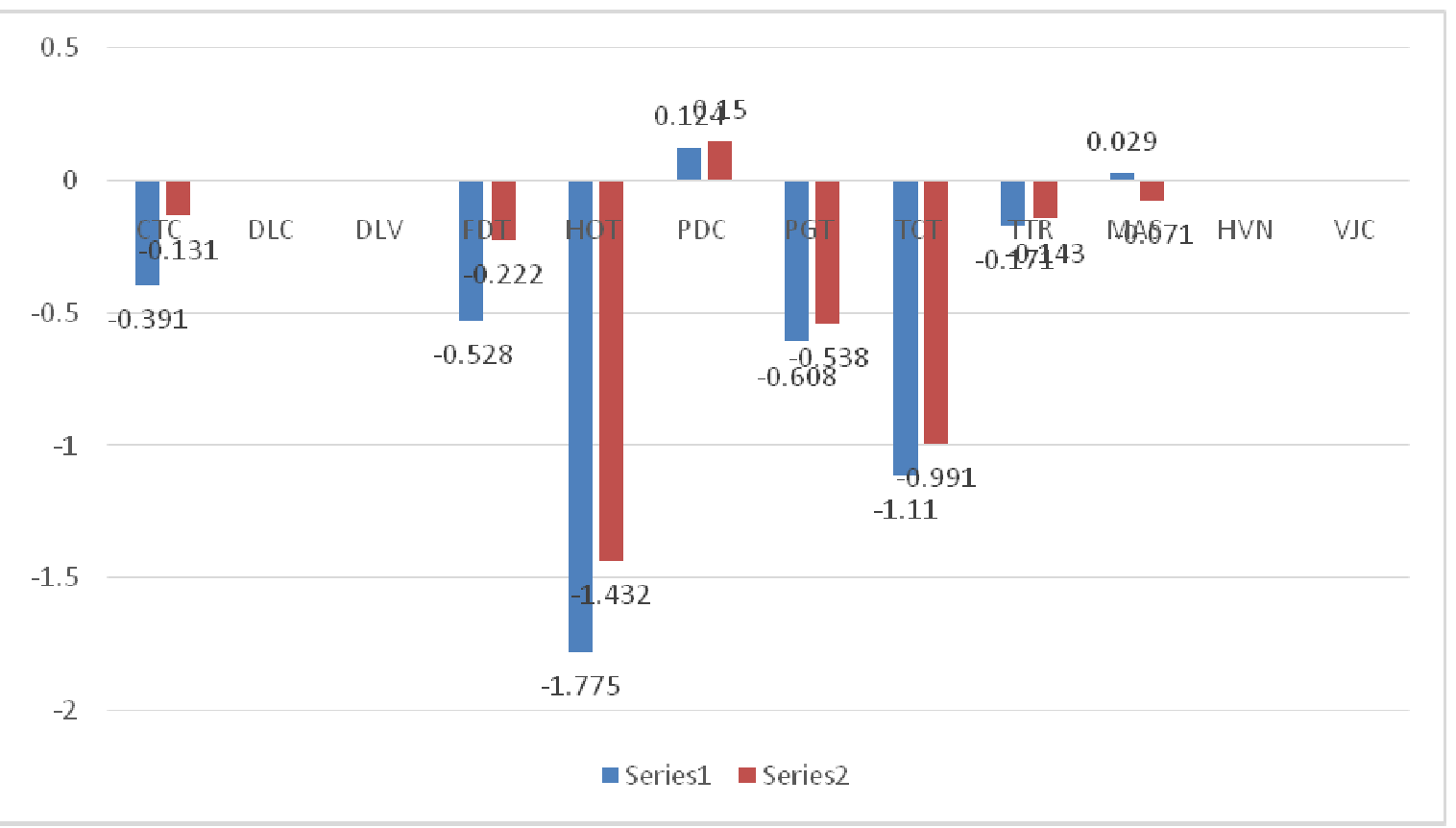

Figure 3: Statistical Results Comparison of Beta CAPM in 2 Periods.

Table 1: Statistical Results (Current Leverage) In 2 Periods

\begin{tabular}{|l|c|c|}
\hline & crisis & Post-L \\
\hline Equity beta max & 1.207 & 0.654 \\
\hline Asset beta max & 1.084 & 0.488 \\
\hline Equity beta mean & 0.605 & 0.092 \\
\hline Asset beta mean & 0.43 & 0.059 \\
\hline
\end{tabular}


What we can analyze from the above data and below chart is that:

Mean asset beta values with current FL has acceptable values. 7/12 firms with beta $<1$. This is good number.

Moreover, mean value of beta CAPM is $0.092<1$.

In addition, the following chart shows equity beta var ,i.e fluctuation of risk, in post - L are smaller than those in the crisis.

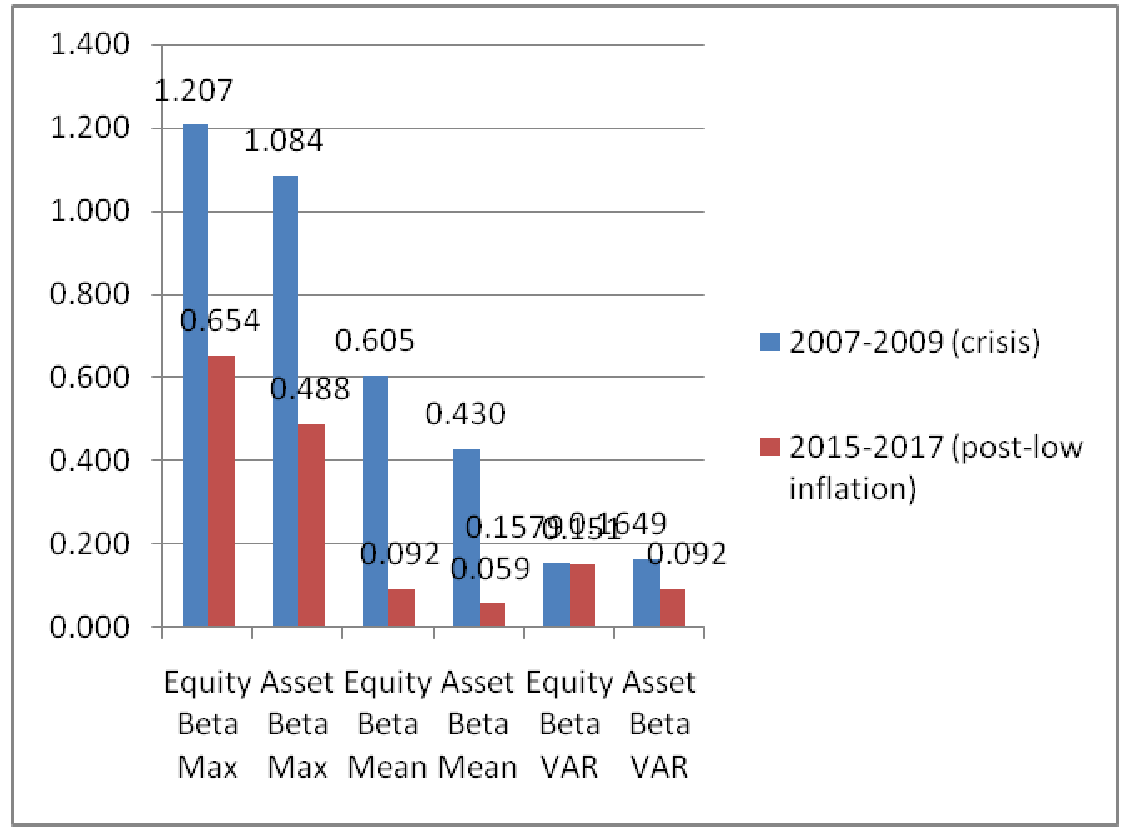

Figure 4: Statistics of Beta CAPM in 2 Periods.

\section{Discussion for Further Researches}

\section{Risk Analysis}

Based on above charts and analysis, we need risk management plan to control the risk fluctuation in this case in the context the Covid 19 and commerce war still has compounding impacts.

\section{IT Security and Risk Management}

Monitoring information security is one of the important technical solutions with practical significance in strengthening the capacity to ensure security for agencies and organizations.

Cyber security threats are becoming hotter in recent years in which there are more IT hackers and viruses as well assiilegal violations.

Hence, firms need to design, operate and monitor safe and secure network systems, grasp the penetration techniques and prevent and prevent attacks of hackers (hackers) effectively. They design and maintain a firewall system or identify and repair vulnerabilities on the network of the unit, deploy and monitor the attack detection system.

\section{Conclusion and Policy Suggestion}

Looking at exhibit 2-3, we could see GDP of Viet Nam during the period 2007-2011 in the range of 5\%-6.5\% (<7\%). And inflation goes down in 2009 then goes up in later years. Even risk level might be lower than those in crisis before, in the context of compounding impacts from commerce war and corona, we still need to reduce risk of quality of products and 
reputation risk of tourism \& airline companies.

We might note that var and market risk might be lower in 2015-2017 (looking at the above charts and analysis) so we need risk management solutions then. Besides, companies might consider some innovative solutions going together with risk strategies, and utilizing of digital technology and AI.

\section{ACKNOWLEDGEMENTS}

I would like to send special thanks to family, colleagues and friends.

\section{REFERENCES}

1. ADB and Viet Nam Fact Sheet, 2010

2. Anderson. J.E., (2009), Tax Policy and House Price Dynamics, SSRN Working Paper

3. Denis, G., Sebastien, V., \& Sofiane, A. (2019). The Reactive Beta Model, Journal of Financial Research, 10.1111/jfir.12182, 42, 4, (867-867), (2019).

4. Dimitrov V, Jain PC. (2006). The Value Relevance of Changes in Financial Leverage, SSRN Working Paper

5. Eugene FF, French KR. (2004). The Capital Asset Pricing Model: Theory and Evidence,Journal of Economic Perspectives.

6. Flifel, Kaouther., (2012), Financial Markets between Efficiency and Persistence : Empirical Evidence on Daily Data, Asian Journal of Finance and Accounting

7. Hang, B., Hou, K., Kung, H., Erica, X.N., \& Lu, Z. (2018). The CAPM strikes back? An equilibrium model with disasters, Journal of Financial Economics, 131: 269-298.

8. Huy, Dinh T.N., (2013), Estimating Beta of Viet Nam Listed Public Utilities, Natural Gas and Oil Company Groups During and After The Financial Crisis 2007-2011, Economic and Business Review, Vol. 15, No. 1, pp. 5771

9. Huy, Dinh T.N., (2013), Beta of Viet Nam Listed Computer and Electrical Company Groups During and After The Financial Crisis 2007-2011, Asian Journal of Finance \& Accounting, Vol. 5, No. 1, pp. 127-139

10. Shetty,S., \& Janet, J.D.S. (2019). An Empirical Examination of the CAPM on BSE SENSEX Stocks, International Journal of Recent Technology and Engineering (IJRTE),8 (2S10).

11. Tolga C., Nicolas A. P., Jonathan J. R., \&Michael S. (2015). Equity Investing with Targeted Constant Volatility Exposure, SSRN Electronic Journal, 10.2139/ssrn.2614828..

12. Umar. (2011). Profits, Financial Leverage and Corporate Governance,SSRN Working Paper

13. Research

14. Ang, A., Chen, J. (2007). CAPM Over the Long Run: 1926-2001,Journal of Empirical Finance

15. ADB and Viet Nam Fact Sheet, 2010 
16. Narmania, Davit. "Economic Policy Uncertainty and Risk Management in Regulated Sectors." International Journal of Business and General Management (IJBGM) 7.4 (2018): 19-28.

17. DERBALI, ABDELKADER, and SLAHEDDINE HALLARA. "Main determinants of banking profitability in Tunisia before and during the financial crisis of 2007." International Journal of Accounting and Financial Management Research (IJAFMR) 3.1 (2013): 39-56.

18. Pal, Shrabanti. "Behaviour of Financial Metrics of Indian Steel Industry During Pre And Post Financial Crisis Period." International Journal of Financial Management (IJFM) 5.4 (2016): 11-22.

19. Xi, Jun-Yang, and Ching-Chuan Tseng. "RISK MANAGEMENT OF VULNERABILITY THROUGH FUZZY COGNITIVE MAP." International Journal of Financial Management (IJFM) 7.3 (2018):33-40

20. http://www.ifc.org/ifcext/mekongpsdf.nsf/Content/PSDP22

21. http://www.construction-int.com/article/vietnam-construction-market.html

22. http://fia.mpi.gov.vn/Default.aspx? ctl=Article \&MenuID=170\&aID=185\&PageSize $=10 \&$ Page $=0$

23. http://kientruc.vn/tin_trong_nuoc/nganh-bat-dong-san-rui-ro-va-co-hoi/4881.html

24. http://www.bbc.co.uk/vietnamese/vietnam/story/2008/12/081226_vietnam_gdp_down.shtml

25. http://www.mofa.gov.vn/vi/

26. https://www.ceicdata.com/en/indicator/vietnam/real-gdp-growth

\section{Exhibit}

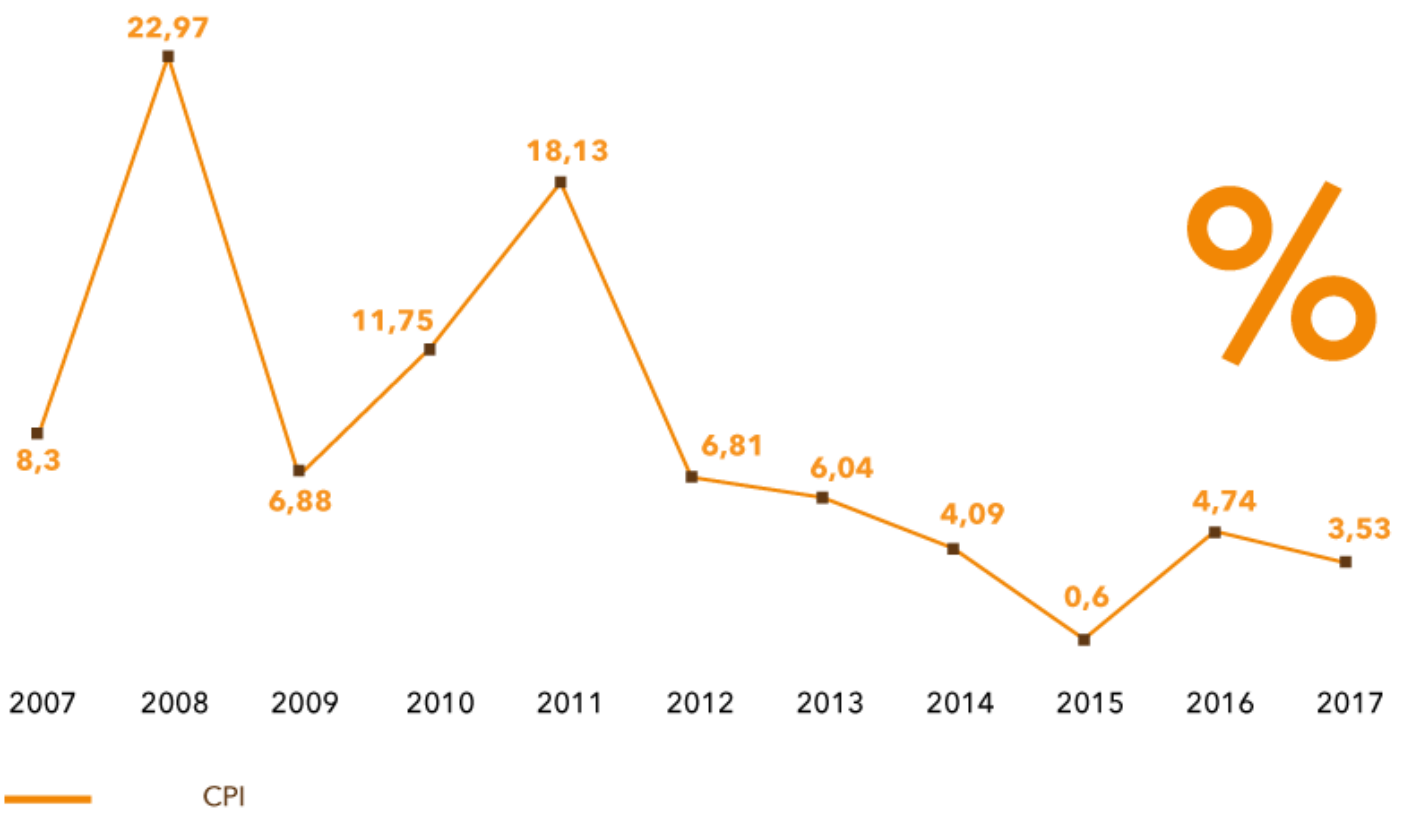

Exhibit 1 - Inflation, CPI Over Past 10 Years (2007-2017) in Vietnam 


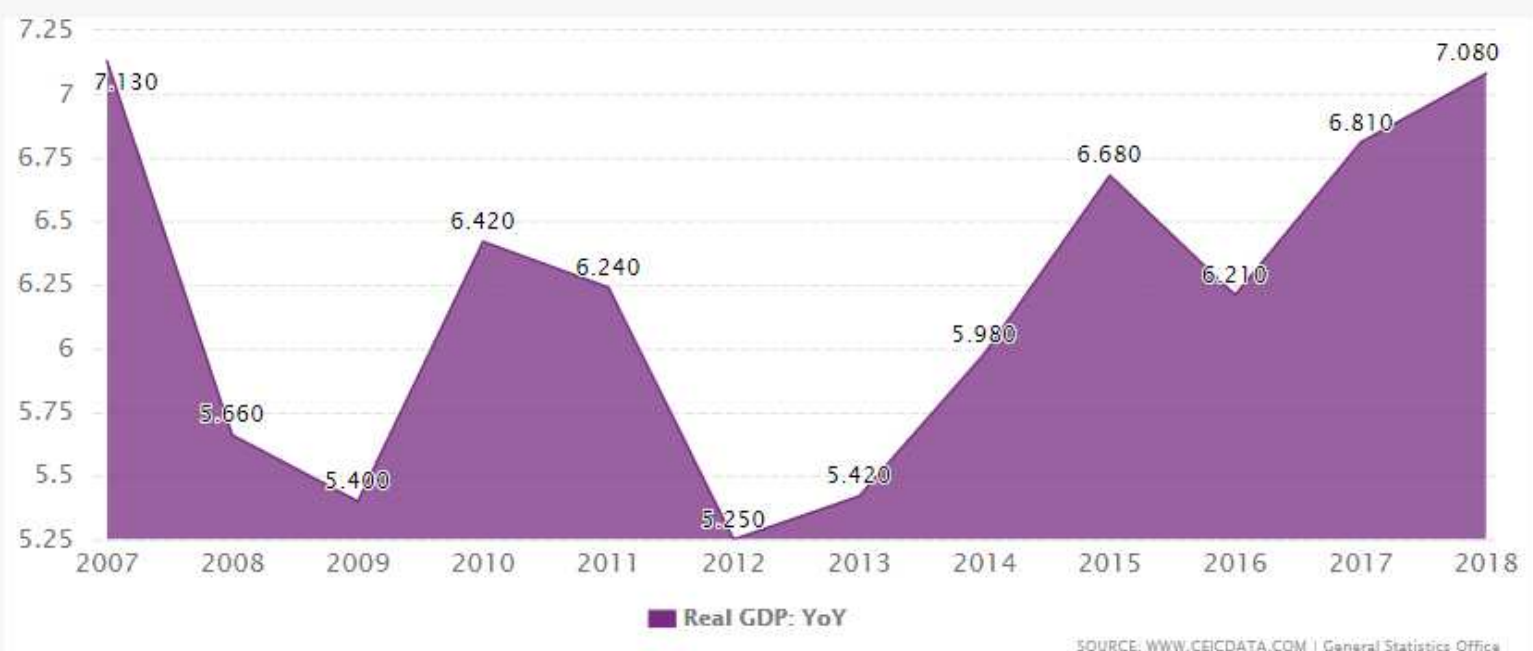

Exhibit 2 - GDP Growth Rate Past 10 Years (2007-2018) in Vietnam

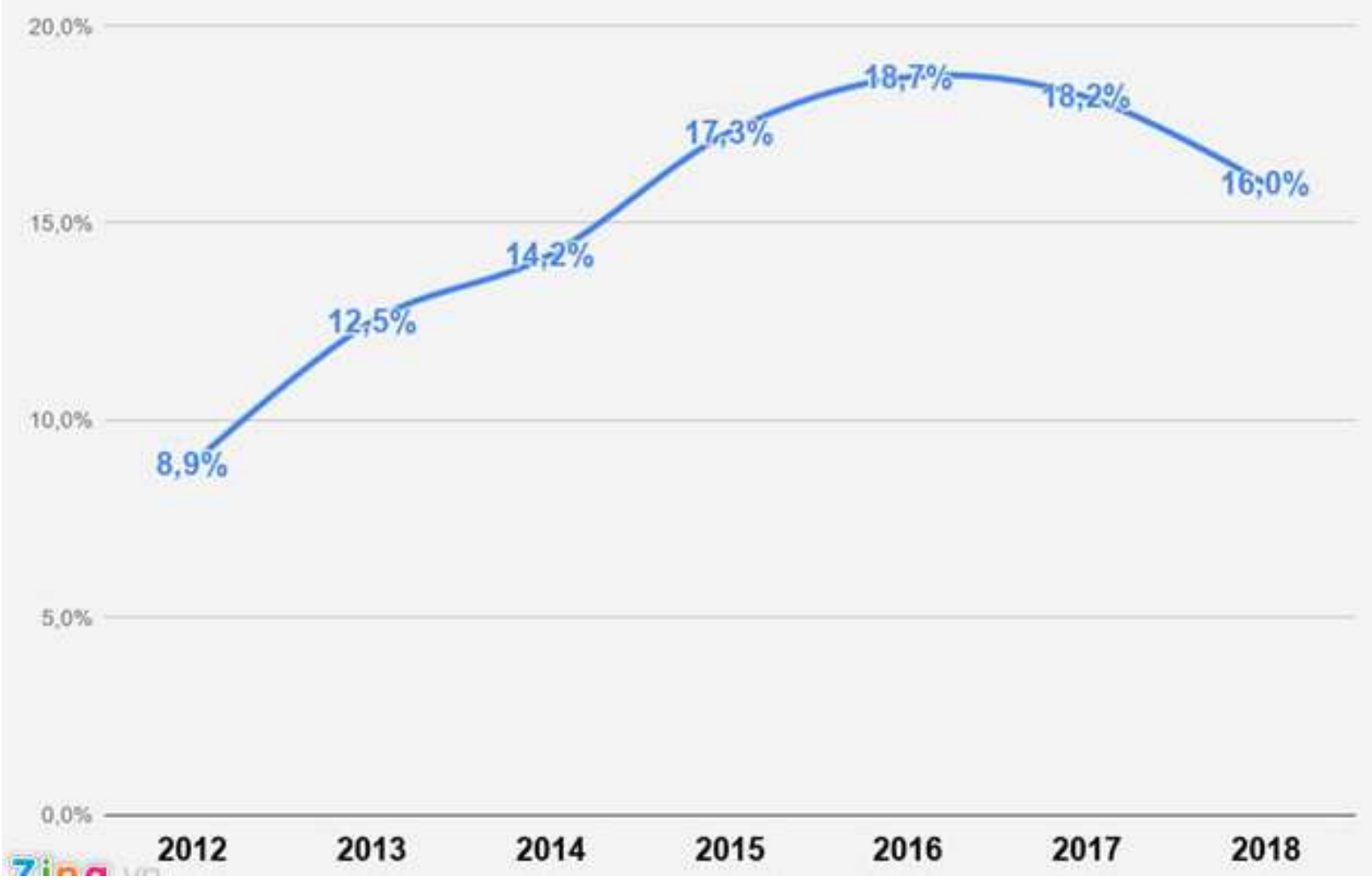

Exhibit 3 - Loan/Credit Growth Rate in the Past Years (2012-2018) in Vietnam. 